\title{
Association of postpartum depression and cesarean section: A systematic review and meta-analysis
}

\author{
Hossein Moameri $^{\mathrm{a}}$, Mohsen Ostadghaderi ${ }^{\mathrm{a}}$, Elham Khatooni ${ }^{\mathrm{a}}$, Amin Doosti-Irani ${ }^{\mathrm{b}, *}$ \\ ${ }^{a}$ Department of Epidemiology and Biostatistics, School of Public Health, Tehran University of Medical Sciences, Tehran, Iran \\ ${ }^{\mathrm{b}}$ Department of Epidemiology, School of Public Health and Research Center for Health Sciences, Hamadan University of Medical Sciences, Hamadan, Iran
}

\section{A R T I C L E I N F O}

\section{Keywords:}

Postpartum depression

Cesarean section

Systematic review

\begin{abstract}
A B S T R A C T
Objectives: Postpartum depression (PPD) is a major depressive disorder. Its symptoms begin 4 weeks after delivery. Several studies have evaluated the association of the type of delivery with PPD; however, there are controversies regarding this association. Therefore, the aim of this systematic review was to estimate the overall association between cesarean section (CS) and PPD.

Methods: The international databases of Medline, Scopus, Web of Science, Science Direct, EMBASE and Ovid were searched until May 2017. Quality assessment was done using the Newcastle-Ottawa Scale. The pooled odds ratio in case-control and relative risk in cohort studies were used as the measures of association. A randomeffects model was applied for the report of the results with $95 \%$ confidence intervals.

Results: Of 989 studies, 32 articles met the eligibility criteria and were included in the review. The adjusted OR of the association between CS and PPD was 1.15 (95\% CI: 1.00, 1.34) and the crude odds ratio of this association was $1.36(1.20,1.55)$. The odds ratio of the association of elective and emergency CS and PPD was 1.29 (1.12, $1.49)$ and $1.36(1.20,1.55)$, respectively. In addition, the pooled relative risk of the association between CS and PPD was $1.22(0.94,1.58)$ in cohort studies.

Conclusions: Based on the results of this meta-analysis, it seems CS, regardless of the type of cesarean, is a risk factor for PPD.
\end{abstract}

\section{Introduction}

According to the last report of the World Health Organization, depression is one of the most common diseases affecting more than 300 million people in the world. ${ }^{1}$ In addition, depression is the most important cause of suicide-related death and results in 800,000 deaths annually. ${ }^{2}$ (PPD) is a common disorder among women in the world. The symptoms of this disease usually begin four weeks after delivery. ${ }^{3}$ Some of the symptoms include anxiety, feeling inefficient in the care of the newborn, inability to cope with the new situation, loss of control, obsessive thoughts, irrational fear, and disappointment. ${ }^{4}$ In addition to negative effects on the mother-infant relationship, inappropriate nutrition, and inadequate growth of the newborn, PPD may cause learning problems for the children of affected mothers. ${ }^{5}$ Moreover, the risk of suicide-related deaths among postpartum depressive women is more than healthy mothers. ${ }^{6}$ On the other hand, mothers who experience PPD are more susceptible to depression in the later stages of their lives. ${ }^{7}$
The burden of PPD in lower and middle-income countries is more than high-income countries. ${ }^{8}$

There are two types of CS including elective and emergent. Elective CS is a medically unnecessary CS, where the pregnant women or her doctor requests this method for delivery. Emergent CS has been defined as an unplanned CS, for example, CS accomplished before the planned date of delivery because of clinical conditions of pregnant women. ${ }^{9}$

Several studies have assessed the association of cesarean section (CS) and PPD. Based on the results of some studies, the type of delivery is associated with PPD. ${ }^{10}$ Mothers who undergo vaginal delivery have a lower risk of PPD than mothers with a CS. The risk of PPD after elective CS is higher than its risk after vaginal delivery, and emergency CS. ${ }^{11}$ Other studies have reported a higher incidence of PPD in mothers with emergency CS compared to elective cesarean and vaginal delivery. ${ }^{12-14}$ Some studies have not shown an association between the type of delivery and PPD. ${ }^{15-17}$

Due to the controversy in the results of the studies and lack of a

\footnotetext{
${ }^{*}$ Corresponding author. Department of Epidemiology, School of Public Health and Research Center for Health Sciences, Hamadan University of Medical Sciences, Hamadan, Zip code: 6517838736, Iran.

E-mail addresses: hossein_moameri67@yahoo.com (H. Moameri), mohsen.ostadghaderi@gmail.com (M. Ostadghaderi), e_kh911@yahoo.com (E. Khatooni), a_doostiirani@yahoo.com, a.doosti@umsha.ac.ir (A. Doosti-Irani).
} 


\section{PRISMA 2009 Flow Diagram}
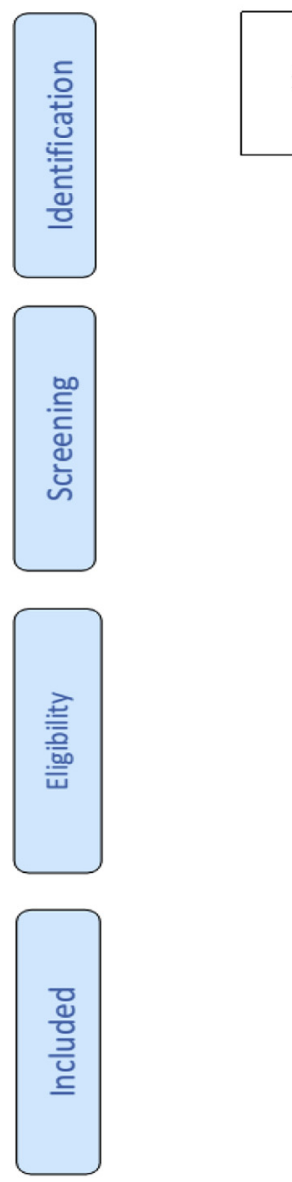

Records identified through international database searching $(\mathrm{n}=905)$

\section{Additional records identified through other sources} $(\mathrm{n}=84)$

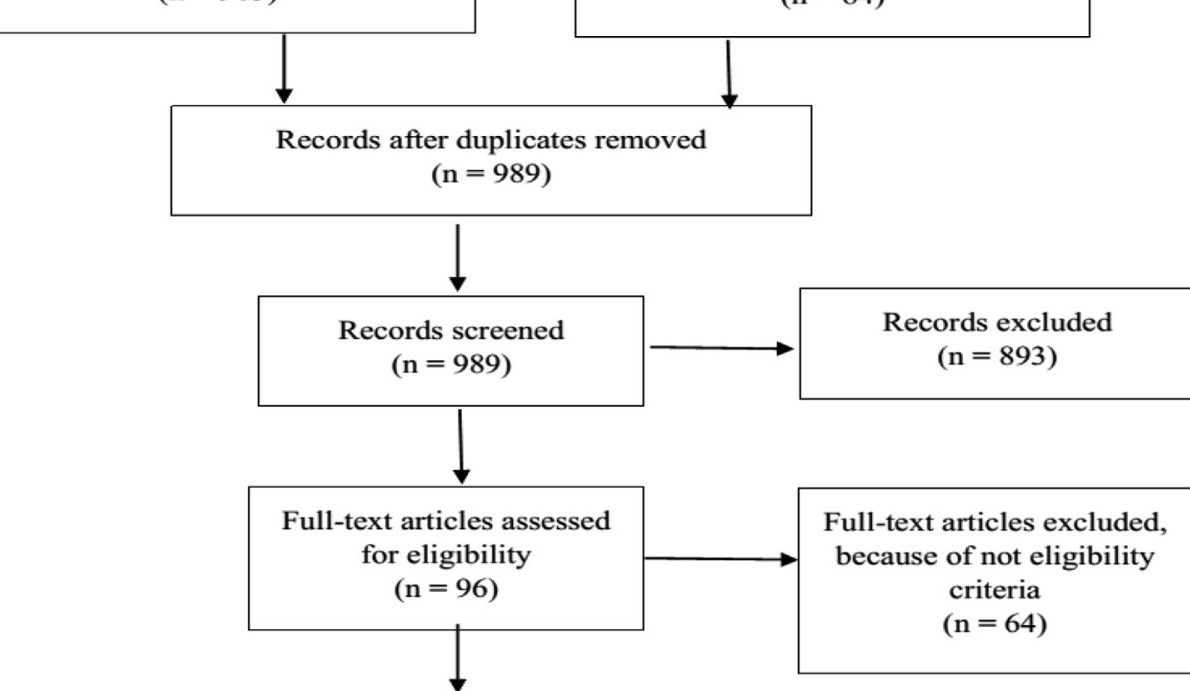

Studies included in qualitative synthesis $(\mathrm{n}=32)$

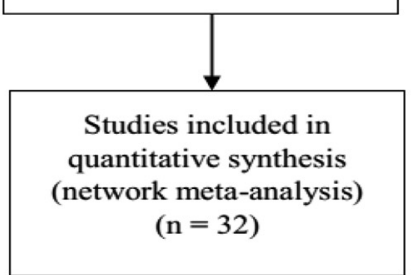

Fig. 1. A flow chart depicting the stages of retrieving articles and checking eligibility criteria for Meta-analyze.

universal consensus regarding the association between CS and PPD, this systematic review aimed to investigate the overall association of CS with PPD.

\section{Methods}

\subsection{Search strategy}

The international electronic databases were searched using a predesigned search strategy. We combined a set of keywords including CS, PPD, cohort, and case-control studies. The databases of Medline (from January 1950 to May 2017), Scopus (from January 1973 to May 2017), Web of Science (from January 1945 to May 2017), Science Direct (from January 1823 to May 2017), EMBASE (from January 1974 to May 2017), and Ovid (from January 1860 to May 2017) were searched. In order to access more resources, the reference lists of selected articles were also scanned and the authors of selected studies were contacted.

\subsection{Selection criteria for studies}

All cohort and case-control studies that assessed the association of the type of delivery and PPD regardless of time, and language of publication were included in this systematic review. The primary outcome was PPD confirmed using standard tools.

\subsection{Data collection and assessment of validity}

Two researchers (HM and MOG) were responsible for screening the retrieved studies independently. They read the titles and abstracts of the studies in order to identify the studies that met the eligibility criteria. Then, the full texts of the selected studies were reviewed and the articles that met the inclusion criterion completely were included in the meta-analysis. Any disagreement between authors was resolved by discussion and judgment of a third author (ADI). The agreement and inter-reliability of the two authors were assessed using the Kappa statistics. The kappa value was $82 \%$.

The following variables were extracted from the selected studies for data analysis. The name of first author, the year of publication, the sample size, average age of the mothers, number of patients of the followings: PPD (+); CS (+) depression $(-)$; CS $(+)$ depression $(+)$; vaginal delivery $(+)$ depression $(+)$; vaginal delivery $(+)$ depression $(-)$. The time of PPD measurement, instruments used to diagnose depression, the adjusted odds ratio (OR) and relative risk (RR) for the association of type of delivery and PPD. Moreover, the adjusted variables for the relationship between CS and depression were extracted. The crude OR and RR of studies that did not report the adjusted OR or $\mathrm{RR}$ was calculated. 


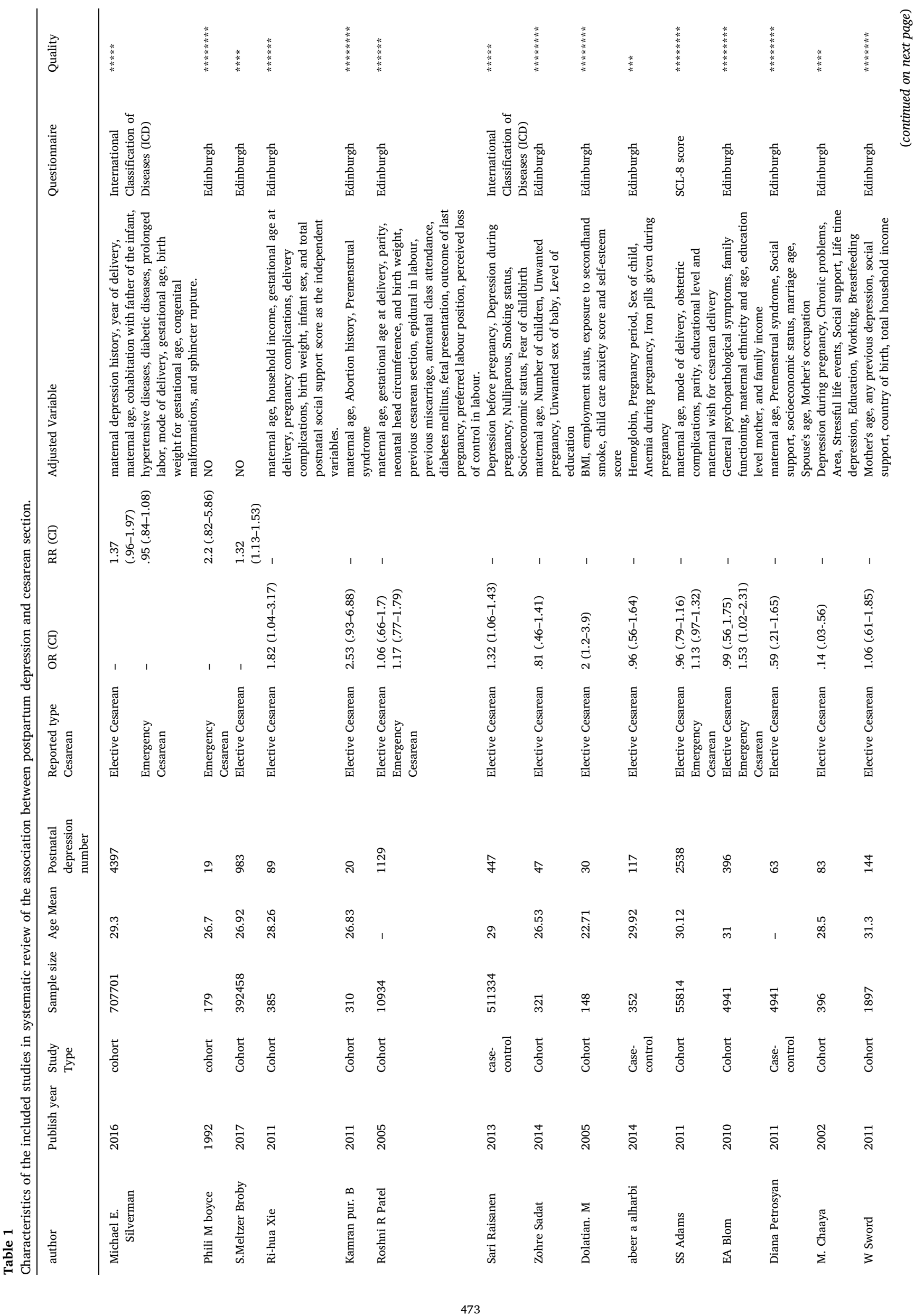




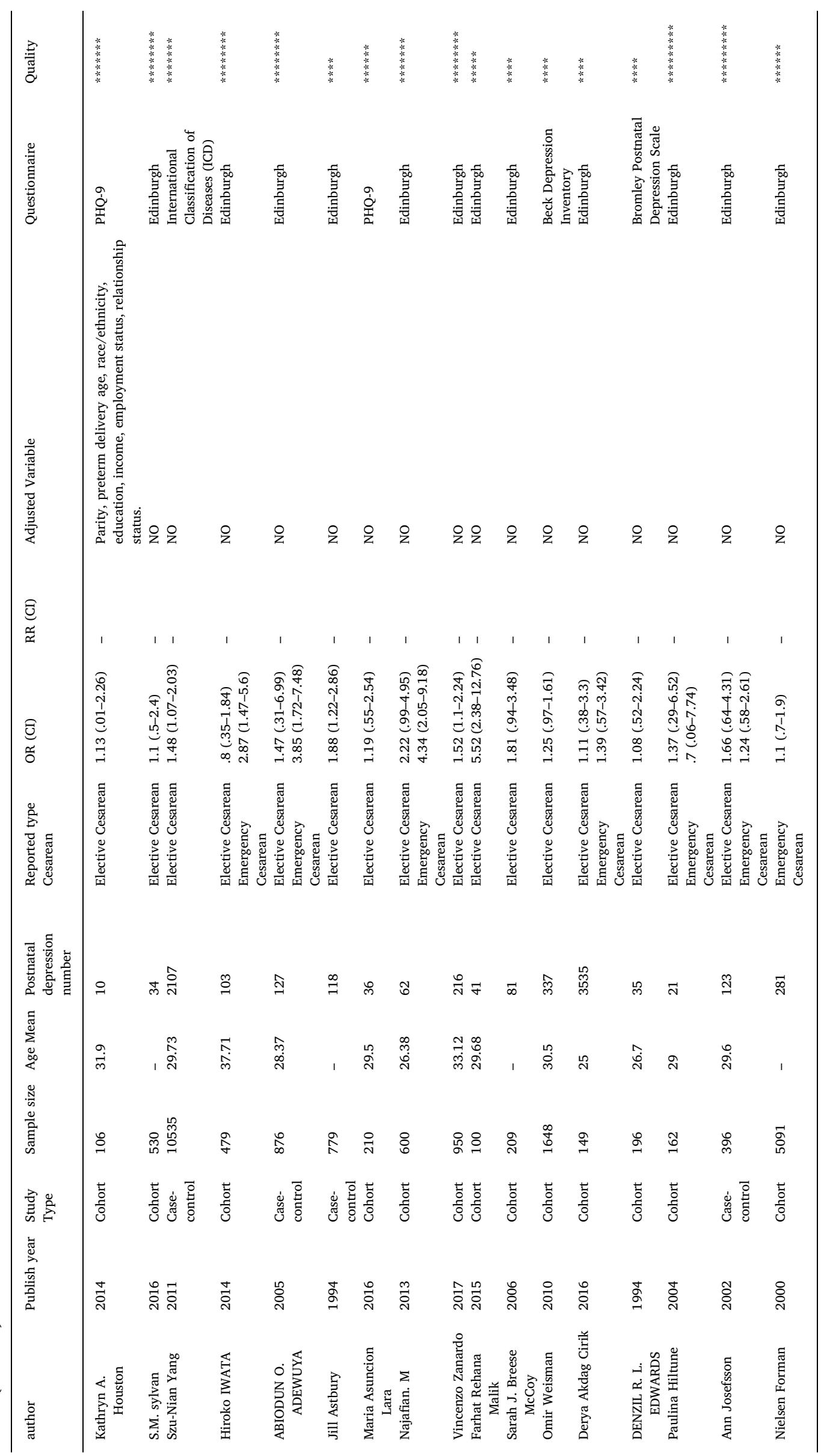



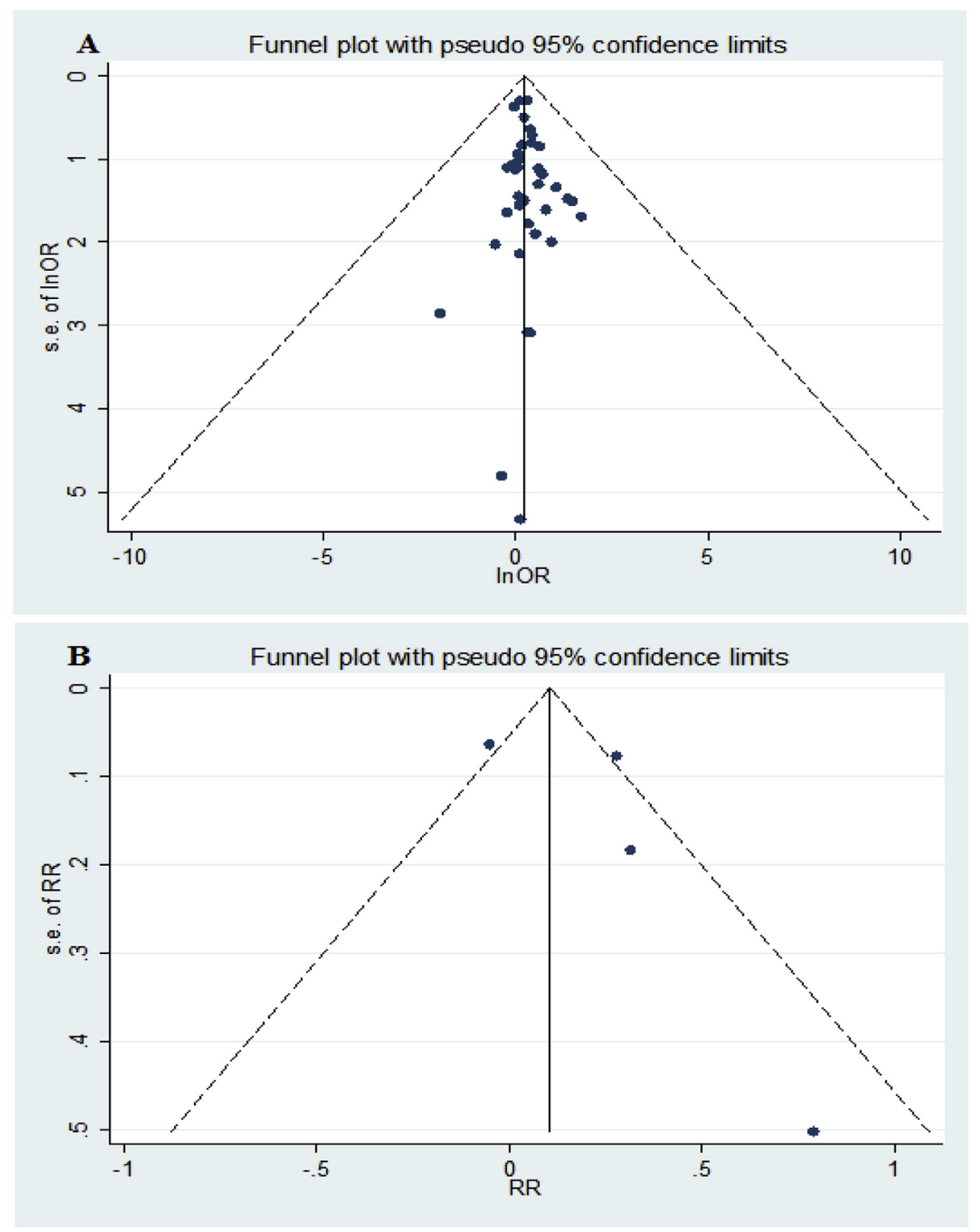

Fig. 2. Funnel Plot of included studies for the association of postpartum depression and cesarean section; A: OR and B: RR.

\subsection{Risk of bias assessment}

We assessed the risk of the bias of the studies using the NewcastleOttawa Scale (NOS). ${ }^{18}$ The following items were for cohort studies: 1) The representativeness of the exposed cohort; 2) Selection of the nonexposed cohort; 3) Ascertainment of exposure; 4) Demonstration that outcome of interest was not present at start of study; 5) Comparability of cohorts on the basis of the design or analysis, 6) Assessment of outcome, 7) Was follow-up long enough for outcomes to occur, and 8) Adequacy of the follow up of cohort studies. In addition, the following items were used for case-control studies: 1) Is the case definition adequate, 2) Representativeness of the cases, 3) Selection of Controls, 4) Definition of Controls, 5) Comparability of cases and controls on the basis of the design or analysis, 6) Ascertainment of exposure, 7) the same method of ascertainment for cases and controls, 8) Non-Response rate.

\section{Data analysis}

\subsection{Heterogeneity and publication bias}

Chi-square test was applied at a significance level of $10 \%$ to assess heterogeneity in the results of the studies. Tau ${ }^{2}$ was used to investigate heterogeneity between the results of studies. Finally, heterogeneity was quantitatively reported using I2 statistics. ${ }^{19}$ Publication bias was assessed using the funnel plot visually and Egger test. ${ }^{20,21}$

\subsection{Measure of association}

A meta-analysis was performed to obtain the pooled measure of association. The pooled odds ratio (OR) and relative risk (RR) were calculated separately with $95 \%$ confidence intervals (CI). A random effects model was applied to report the pooled results. The Stata 11 (Stata Corp, College Station, TX, USA) was used for data analysis. 


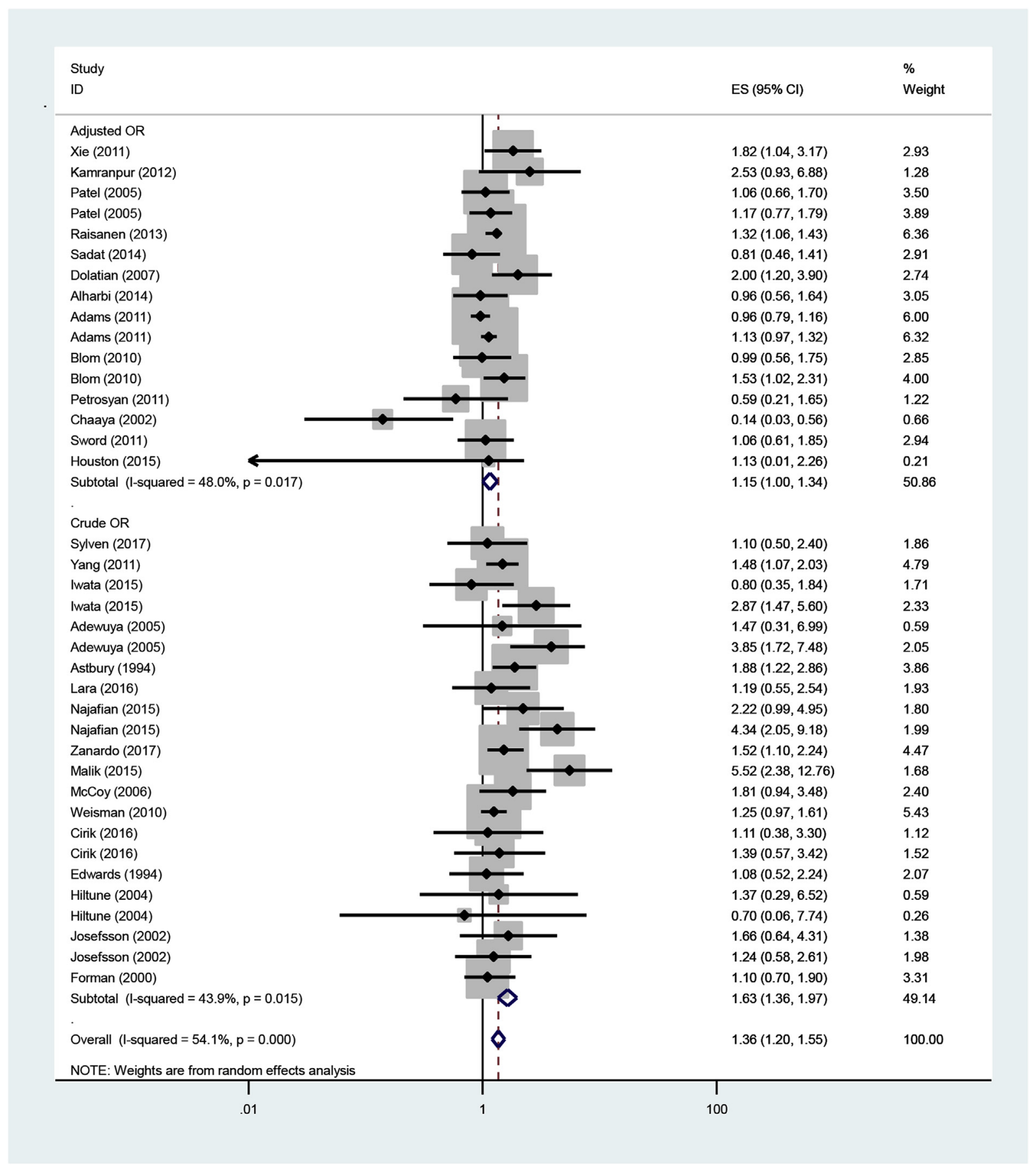

Fig. 3. Forest plot for the association of postpartum depression and cesarean section based on the crude and adjusted OR.

\section{Results}

\subsection{Description of included studies}

In this systematic review, we retrieved 989 cohort and case-control studies, including 905 studies from electronic databases and 84 studies from the list of sources. Of 989 studies, 280 were duplicates, 613 irrelevances to the aim of the study, 55 did not meet the inclusion criteria, and nine lacked the information required to estimate the indicators. Finally, 32 studies (25 cohort studies and 7 case-control

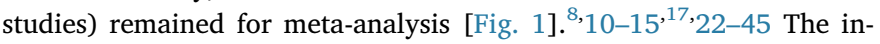
cluded studies involved 1710494 participants. The characteristics of the selected studies are presented in Table 1 .

\subsection{Heterogeneity test}

There was heterogeneity among the results of included studies. The $\mathrm{I}^{2}$ was $57.1 \%$ for studies that reported an odds ratio (OR) and $78.7 \%$ for studies that reported a relative risk (RR). In order to reduce heterogeneity and achieve greater convergence, we performed subgroup analysis based on the type of study, type of CS (elective CS/emergency CS), type of reported indicator (adjusted/crude), method of outcome recognition (self-report/questionnaire), tools used to diagnose depression, and the quality of studies. 


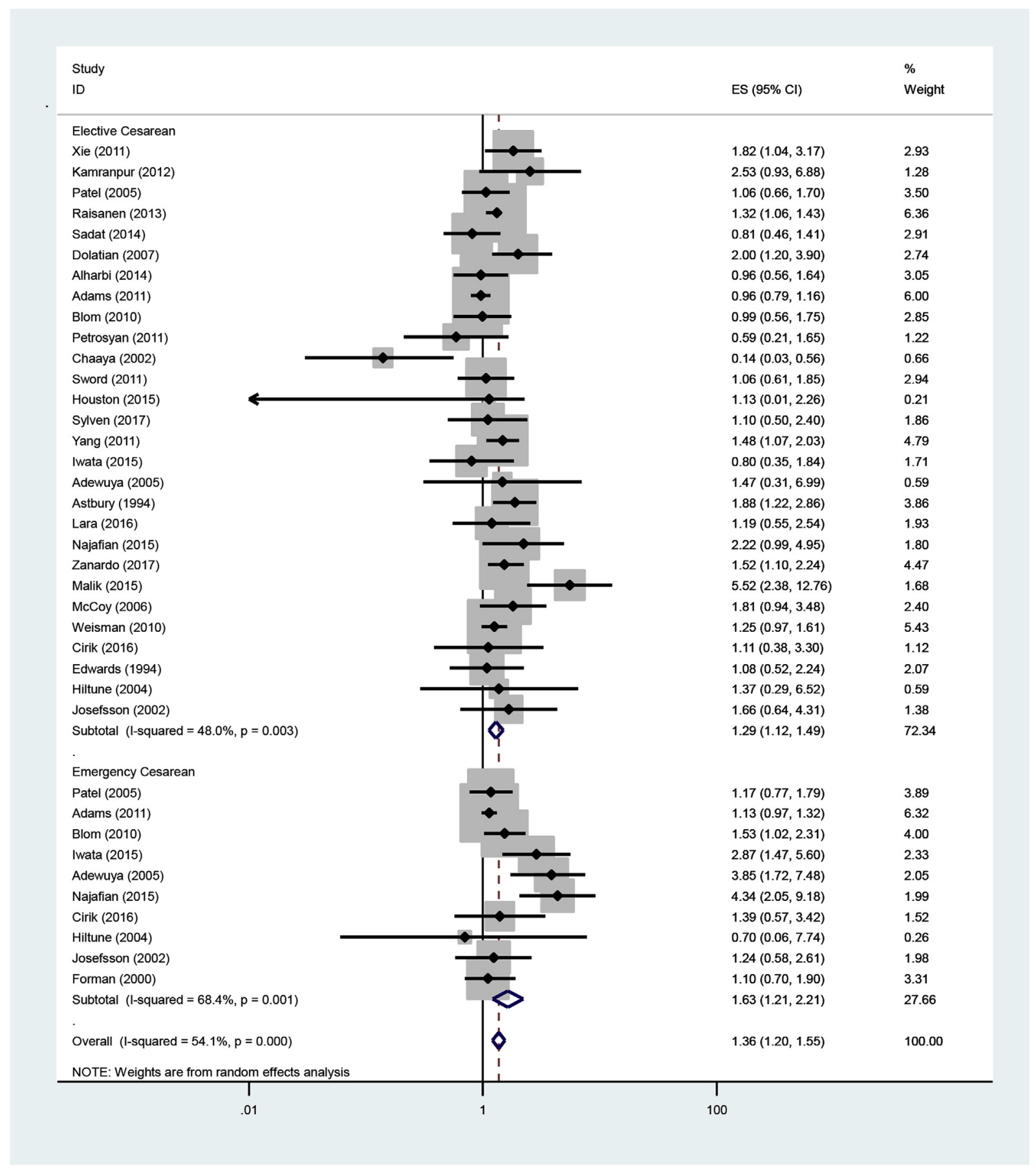

Fig. 4. Forest plot of the pooled odds ratio for the association of postpartum depression and cesarean section based on the type of cesarean.

Table 2

Subgroup analysis for the relationship between postpartum depression and cesarean section, based on the type of the used questionnaire and quality of the included studies.

\begin{tabular}{lllll}
\hline Variable & OR & $95 \%$ CI & I2 (\%) & p-value* \\
\hline Used questionnaire & & & & \\
$\quad$ Edinburgh Postnatal Depression Scale & 1.46 & $1.21,1.76$ & 54.7 & $<0.001$ \\
$\quad$ Other questionnaires & 1.19 & $1.07,1.32$ & 22.8 & $<0.24$ \\
Quality of studies & & & & \\
$\quad$ High & 1.40 & $1.21,1.61$ & 56.1 & $<0.001$ \\
$\quad$ Low & 1.23 & $.90,1.67$ & 51.5 & $<0.16$ \\
\hline
\end{tabular}

*p-value for heterogeneity test.

\subsection{Publication bias}

The results of statistical tests for both OR (Begg: $\mathrm{p}=0.642$, Egger: $\mathrm{p}=0.182$ ) and RR (Begg: $\mathrm{p}=0.497$, Egger: $\mathrm{p}=0.408$ ) indicated a lack of publication bias. In addition, in the funnel plot, the results of studies scattered nearly symmetrically on both sides of the null lines [Fig. 2].

\subsection{Measures of association}

The adjusted pooled OR was 1.15 (95\% CI: 1.00, 1.34) and the crude pooled OR ratio was 1.36 (95\% CI: 1.20, 1.55), for CS [Fig. 3]. The overall odds ratio based on the type of CS was 1.29 (95\% CI: 1.12, 


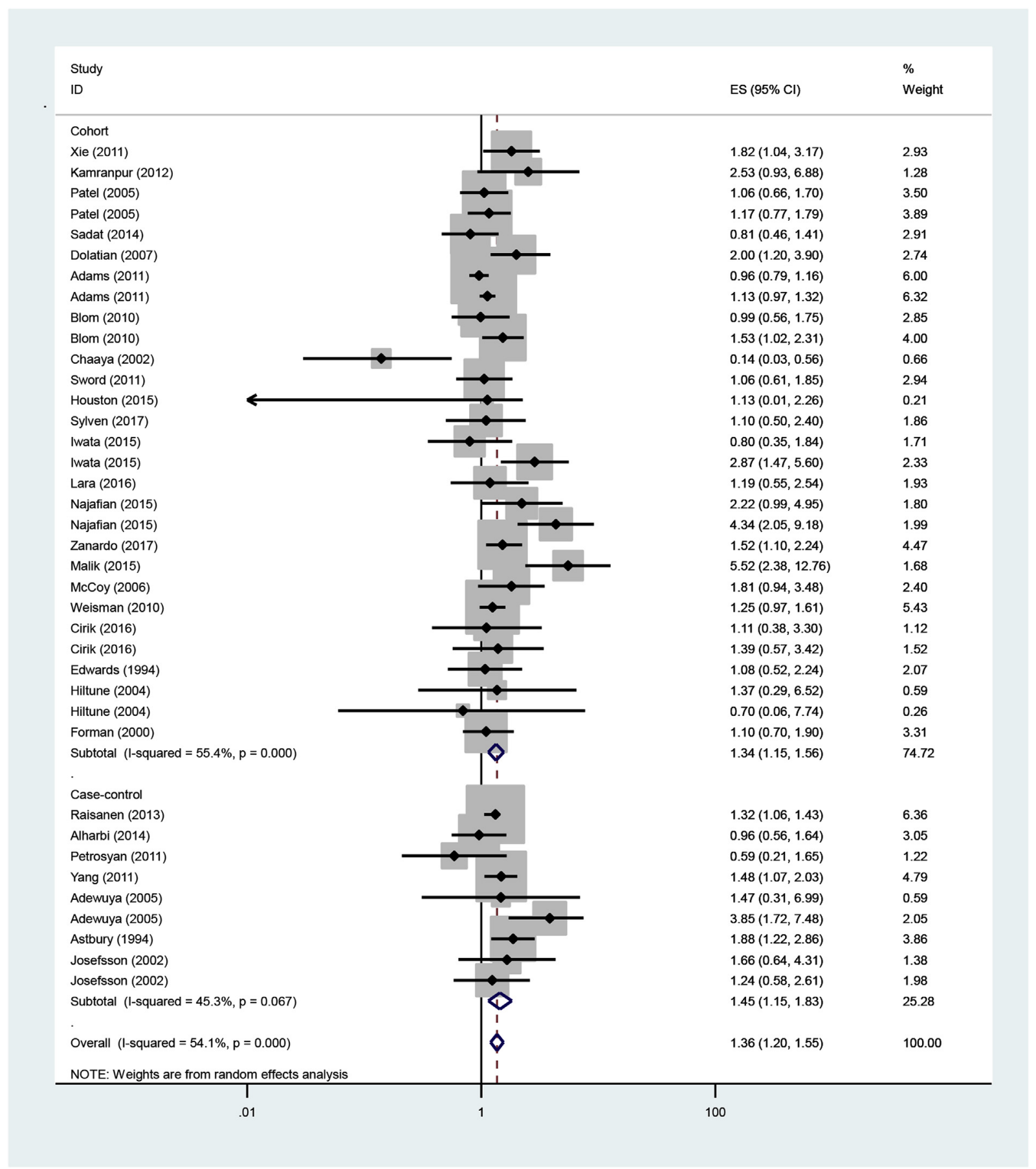

Fig. 5. Forest plot of the pooled odds ratio for the association of postpartum depression and cesarean section based on the type of study design.

1.49) and 1.36 (95\% CI: $1.20,1.55)$ for the elective CS and emergency CS respectively [Fig. 4]. Moreover, the pooled relative risk (RR) was 1.22 (95\% CI: $0.94,1.58$ ) for CS.

In addition, we performed a subgroup analysis based on the type of tools applied to diagnose depression and the quality of the included studies. The pooled odds ratio for studies using Edinburgh Postnatal Depression Scale and other tools was 1.46 (95\% CI: 1.21, 1.76; $\left.\mathrm{I}^{2}=54.7 \%\right)$ and 1.19 (95\% CI: $\left.1.07,1.32 ; \mathrm{I}^{2}=22.8 \%\right)$, respectively (Table 2). The pooled odds ratio based on the type of study was 1.34 (95.1\% CI: $1.15,1.56)$ and 1.45 (95\% CI: $1.15,1.83)$ for cohort and case-control studies respectively [Fig. 5].

\section{Discussion}

We found an association between CS and PPD. This association was observed in the meta-analysis of both case-control and cohort studies. CS is associated with some biological changes in the mother's body, including a decrease in the level of prolactin and an increase in the level of interleukin- $6 .{ }^{46}$ These changes sever risk factors for PPD. ${ }^{47}$ In addition, the CS is a risk factor for hemorrhage that increases the probability of PPD. ${ }^{48}$ Moreover, CS increases the risk of infant mortality ${ }^{49}$; therefore, this factor might increase the risk of PPD and explain our results.

Failure in breastfeeding ${ }^{50}$ and postpartum bleeding ${ }^{51}$ are two reasons for maternal complications after delivery, which may also affect PPD after. In this regard, our results are in line with the findings of 
other studies. $^{22}$

Moreover, the results of our analysis showed that mothers who had an emergency CS had a higher risk of PPD than those who had an elective CS. Among factors affecting the choice of CS are social support, high household income, mother's education, father's education, and occupation. ${ }^{52}$ On the other hand, low socioeconomic status is a risk factor for PPD. ${ }^{53}$ Therefore, it is likely that mothers who have an emergency CS have a lower socioeconomic status than those who undergo selective surgery and are more prone to PPD. This relationship was also confirmed in a study conducted in the Netherlands in which the odds ratio of PPD was higher mothers with CS $(\mathrm{OR}=1.53){ }^{13}$ However, a study in Taiwan reported the opposite; in this study, the odds ratio of depression was higher in mothers that received elective CS $(\mathrm{OR}=1.48)$ than mothers who underwent emergency $\mathrm{CS} .{ }^{11}$

Our results indicated CS is a risk factor for PPD; however, other justification might be as follow: women with a tendency of depression may be generally anxious about delivery. Nowadays high request of CS is a major problem. However, the high rate of CS is not limited to the CS on request; women with some background tendencies may more frequently choose CS. Thus, not the CS itself but the temper/physiological background that leads to CS may also be associated with depression on some pregnant women.

The strengths of this study were the appropriate number of studies included in the final analysis, especially cohort studies, reporting adjusted and crude indicators separately, presenting the relationship between the type of CS and PPD separately, and analyzing studies based on their quality.

There are some limitations for this systematic review and metaanalysis. Firstly, $25 \%$ of the included studies had low quality; this issue may increase the risk of information bias. Secondary, the use of different tools for the diagnosis of PPD in the included studies so the pooled measure of association may increase the risk of information bias. However, we categorized studies based on the used tool for diagnosis of depression, 32 studies have been used Edinburgh Postnatal Depression Scale and 10 studies have been used the Patient Health Questionnaire (PHQ-9), the Beck Depression Inventory (BDI), and the Bromley Postnatal Depression Scale (BPDS). In the latter group because of the low number of studies, we could not conduct subgroup analysis. The third limitation was related to the type of reported measure of association, 18 studies reported the crude measure of association, so the confounding variables in these studies may affect the association of CS and PPD.

\section{Conclusion}

Based on the results of this meta-analysis, it seems CS is a risk factor for PPD. Therefore, it is recommended that decision-makers in the health system pay more attention to the CS and design long-term plans to reduce the rate of unnecessary CSs.

\section{Funding}

None.

\section{Conflicts of interest}

All authors declare no conflict of interest.

\section{Acknowledgement}

We would like to thanks from department of epidemiology and biostatistics of school of public health in Tehran University of medical sciences for the technical support.

\section{References}

1. WHO. Depression: Let's Talk Vol 22. 2017; 2017 August 2017

2. WHO. Depression. Vol 22. 2017; 2017 August 2017.

3. Association AP. Diagnostic and Statistical Manual of Mental Disorders (DSM-5 ${ }^{\circledR}$ ). American Psychiatric Pub; 2013.

4. Miller LJ. Postpartum depression. J Am Acad 2002·287:762-765.

5. Gaffney KF, Kitsantas P, Brito A, Swamidoss CS. Postpartum depression, infant feeding practices, and infant weight gain at six months of age. J Pediatr Health Care. 2014;28:43-50.

6. Almond P. Postnatal depression: a global public health perspective. Perspect public health. 2009;129:221-227.

7. Woods NF, Smith-DiJulio K, Percival DB, Tao EY, Mariella A, Mitchell ES. Depressed mood during the menopausal transition and early postmenopause: observations from the Seattle Midlife Women's Health Study. Menopause. 2008;15:223-232.

8. Lara MA, Navarrete L, Nieto L. Prenatal predictors of postpartum depression and postpartum depressive symptoms in Mexican mothers: a longitudinal study. Arch Wom Ment Health. 2016;19:825-834

9. Lagrew DC, Bush MC, McKeown AM, Lagrew NG. Emergent (crash) cesarean delivery: indications and outcomes. Am J Obstet Gynecol. 2006;194:1638-1643 discussion 1643.

10. Cirik DA, Yerebasmaz N, Kotan VO, et al. The impact of prenatal psychologic and obstetric parameters on postpartum depression in late-term pregnancies: a preliminary study. Taiwan J Obstet Gynecol. 2016;55:374-378.

11. Yang S-N, Shen L-J, Ping T, Wang Y-C, Chien C-W. The delivery mode and seasonal variation are associated with the development of postpartum depression. $J$ Affect Disord. 2011;132:158-164.

12. Najafian M, Cheraghi M, Namazi M. A study on the relationship of postpartum depression and method of delivery. Jundishapur Sci Med J. 2014;13.

13. Blom E, Jansen P, Verhulst F, et al. Perinatal complications increase the risk of postpartum depression. Gener R Study BJOG An Int J Obstet Gynaecol. 2010;117:1390-1398.

14. Iwata H, Mori E, Tsuchiya M, et al. Predicting early post-partum depressive symptoms among older primiparous Japanese mothers. Jpn J Nurs Sci. 2015:12:297-308.

15. Alharbi AA, Abdulghani HM. Risk factors associated with postpartum depression in the Saudi population. Neuropsychiatric Dis Treat. 2014;10:311.

16. Goker A, Yanikkerem E, Demet MM, Dikayak S, Yildirim Y, Koyuncu FM. Postpartum depression: is mode of delivery a risk factor? ISRN Obstet Gynecol. 2012;2012.

17. Josefsson A, Angelsiöö L, Berg G, et al. Obstetric, somatic, and demographic risk factors for postpartum depressive symptoms. Obstet Gynecol. 2002;99:223-228.

18. Stang A. Critical evaluation of the Newcastle-Ottawa scale for the assessment of the quality of nonrandomized studies in meta-analyses. Eur J Epidemiol. 2010;25:603-605.

19. Higgins JP, Thompson SG, Deeks JJ, Altman DG. Measuring inconsistency in metaanalyses. BMJ Br Med J (Clin Res Ed). 2003;327:557.

20. Egger M, Smith GD, Schneider M, Minder C. Bias in meta-analysis detected by a simple, graphical test. Br Med J. 1997;315:629-634.

21. Begg CB, Mazumdar M. Operating characteristics of a rank correlation test for publication bias. Biometrics. 1994:1088-1101.

22. Räisänen S, Lehto SM, Nielsen HS, Gissler M, Kramer MR, Heinonen S. Fear of childbirth predicts postpartum depression: a population-based analysis of 511422 singleton births in Finland. Br Med J open. 2013;3:e004047.

23. Patel RR, Murphy DJ, Peters TJ. Operative delivery and postnatal depression: a cohort study. Br Med J. 2005;330:879

24. Adams S, Eberhard-Gran M, Sandvik A, Eskild A. Mode of delivery and postpartum emotional distress: a cohort study of 55814 women. BJOG An Int J Obstet Gynaecol 2012;119:298-305.

25. Adewuya AO, Fatoye FO, Ola BA, Ijaodola OR, Ibigbami S-MO. Sociodemographic and obstetric risk factors for postpartum depressive symptoms in Nigerian women. $J$ Psychiatr Pract. 2005;11:353-358.

26. Astbury J, Brown S, Lumley J, Small R. Birth events, birth experiences and social differences in postnatal depression. Aust N Z J Public Health. 1994;18:176-184.

27. Boyee $\mathrm{P}$, Todd A. Increased risk of postnatal depression after emergency Cesarean section. Med J Aust. 1992;156:172-174.

28. Chaaya M, Campbell O, El Kak F, Shaar D, Harb H, Kaddour A. Postpartum depression: prevalence and determinants in Lebanon. Arch Wom Ment Health. 2002;5:65-72.

29. Edwards DR, Porter S-AM, Stein GS. A pilot study of postnatal depression following caesarean section using two retrospective self-rating instruments. $J$ Psychosom Res. 1994;38:111-117.

30. Hiltunen P, Raudaskoski T, Ebeling H, Moilanen I. Does pain relief during delivery decrease the risk of postnatal depression? Acta Obstet Gynecol Scand. 2004;83:257-261.

31. Houston KA, Kaimal AJ, Nakagawa S, Gregorich SE, Yee LM, Kuppermann M. Mode of delivery and postpartum depression: the role of patient preferences. Am J Obstet Gynecol. 2015;212:229 e221-229. e227.

32. Kamranpour SB, Shakiba M. Cesarean section and post partum depression. Iran $J$ Obstet Gynecol Infertil. 2012;15:60-67.

33. Malik FR, Malik BB, Irfan M. Comparison of postnatal depression in women following normal vaginal delivery and caesarean section: a pilot study. J Postgrad Med Inst. $2015 ; 29$.

34. McCoy SJB, Beal JM, Shipman SBM, Payton ME, Watson GH. Risk factors for postpartum depression: a retrospective investigation at 4-weeks postnatal and a review of the literature. J Am Osteopath Assoc. 2006;106:193.

35. Meltzer-Brody S, Maegbaek M, Medland S, Miller W, Sullivan P, Munk-Olsen T 
Obstetrical, pregnancy and socio-economic predictors for new-onset severe postpartum psychiatric disorders in primiparous women. Psychol Med. 2017;47:1427-1441.

36. Nielsen D, Videbech P, Hedegaard M, Dalby J, Secher N. Postpartum depression: identification of women at risk. BJOG An Int J Obstet Gynaecol. 2000;107:1210-1217.

37. Petrosyan D, Armenian HK, Arzoumanian K. Interaction of maternal age and mode of delivery in the development of postpartum depression in Yerevan, Armenia. J Affect Disord. 2011;135:77-81.

38. Sadat Z, Kafaei Atrian M, Masoudi Alavi N, Abbaszadeh F, Karimian Z, Taherian A. Effect of mode of delivery on postpartum depression in Iranian women. $J$ Obstet Gynaecol Res. 2014;40:172-177.

39. Silverman ME, Reichenberg A, Savitz DA, et al. The risk factors for postpartum depression: a population-based study. Depress Anxiety. 2017;34:178-187.

40. Sword W, Kurtz Landy C, Thabane L, et al. Is mode of delivery associated with postpartum depression at 6 weeks: a prospective cohort study. BJOG An Int J Obstet Gynaecol. 2011;118:966-977.

41. Sylvén S, Thomopoulos T, Kollia N, Jonsson M, Skalkidou A. Correlates of postpartum depression in first time mothers without previous psychiatric contact. Eur Psychiatry. 2017;40:4-12.

42. Weisman O, Granat A, Gilboa-Schechtman E, et al. The experience of labor, maternal perception of the infant, and the mother's postpartum mood in a low-risk community cohort. Arch Wom Ment Health. 2010;13:505-513.

43. Xie R-h, Lei J, Wang S, Xie H, Walker M, Wen SW. Cesarean section and postpartum depression in a cohort of Chinese women with a high cesarean delivery rate. $J$ Wom Health. 2011;20:1881-1886.

44. Zanardo V, Giliberti L, Volpe F, Parotto M, Luca F, Straface G. Cohort study of the depression, anxiety, and anhedonia components of the Edinburgh Postnata Depression Scale after delivery. Int J Gynecol Obstet. 2017;137:277-281.

45. Dolatian MMP, Alavi Majd H, Yazdjerdi M. Relationship between type of delivery and postpartum depression. J Reproduction Infertil. 2006;7:260-268.

46. Hebisch G, Neumaier-Wagner PM, Huch R, von Mandach U. Maternal serum interleukin-1 $\beta,-6$ and-8 levels and potential determinants in pregnancy and peripartum. $J$ Perinat Med. 2004;32:475-480.

47. Triebel J, Martínez de la Escalera G, Clapp C, Bertsch T. Vasoinhibins may contribute to postpartum depression. Front Psychiatry. 2017;8:167.

48. Eckerdal P, Kollia N, Löfblad J, et al. Delineating the association between heavy postpartum haemorrhage and postpartum depression. PLoS One. 2016;11:e0144274.

49. Xie Rh, Gaudet L, Krewski D, Graham ID, Walker MC, Wen SW. Higher cesarean delivery rates are associated with higher infant mortality rates in industrialized countries. Birth. 2015;42:62-69.

50. Wallenborn JT, Masho SW. The interrelationship between repeat cesarean section, smoking status, and breastfeeding duration. Breastfeed Med. 2016;11:440-447.

51. Belachew J, Eurenius K, Mulic-Lutvica A, Axelsson O. Placental location, postpartum hemorrhage and retained placenta in women with a previous cesarean section delivery: a prospective cohort study. Ups J Med Sci. 2017:1-5.

52. Rajabi A, Maharlouei N, Rezaianzadeh A, Rajaeefard A, Gholami A. Risk factors for C-section delivery and population attributable risk for C-section risk factors in Southwest of Iran: a prospective cohort study. Med J Islam Repub Iran. 2015;29:294.

53. Jin Q, Mori E, Sakajo A. Risk factors, cross-cultural stressors and postpartum depression among immigrant Chinese women in Japan. Int $J$ Nurs Pract. 2016;22:38-47. 